\title{
The Fakability of Bar-On's Emotional Quotient Inventory Short Form: Catch Me if You Can
}

\author{
W. Lee Grubb III \\ East Carolina University \\ Michael A. McDaniel \\ Virginia Commonwealth University
}

\begin{abstract}
This study investigated the fakability of the Emotional Quotient Inventory Short Form (EQ-i:S), a mixed-model emotional intelligence test developed by Bar-On (2002). A sample of 229 undergraduate students from a southeastern university completed a battery of selection and assessment measures in both an honest and faking good condition. When responded to honestly, the EQ-i:S is predicted by The Big Five with a multiple correlation of .79. Therefore, the EQ-i:S can be viewed as an aggregation of The Big Five constructs. When faking, respondents were able to improve scores on the EQ-i:S, each of its subtests, and each of The Big Five measures. Respondents improved scores on the EQ-i:S by .83 SD. Faking on the EQ-i:S was primarily predicted by cognitive ability and agreeableness. The relative ease with which respondents can substantially raise their scores limits the value of the EQ-i:S as an applicant screening tool. The substantial extent to which the EQ-i:S is predicted by The Big Five casts doubt on the construct of emotional intelligence as operationalized in the EQ-i:S.
\end{abstract}

As the use of emotional intelligence tests in industry continues to increase, the debate over the validity of emotional intelligence tests continues as well. Emotional intelligence tests have been used to predict leadership style, emergent leadership, and leadership perceptions (Barling, Slater, \& Kelloway, 2002; Humphrey, 2002; Kellett, Humphrey, \& Sleeth, 2002; Wolf, Pescosolido, \& Druskat, 2002) and have

Correspondence should be sent to W. Lee Grubb III, East Carolina University, College of Business, Department of Management, 323 Slay Building, Greenville, NC 27858. E-mail: grubbw@ecu.edu 
been discussed as predictors of job performance (Bar-On, 1997, 2002; Goleman, 1998). In recent years, however, there has been some debate about the effectiveness of emotional intelligence for predicting future job performance. Emotional intelligence tests have been compared to cognitive tests, and Goleman (1998) argued that one's emotional intelligence accounts for more variance in individual and group performance than tests of cognitive ability. Similarly, the Emotional Quotient Inventory (EQ-i), a measure developed by Bar-On (1997) to assess emotional intelligence, was found to be a predictor of job performance (Bachman, Stein, Campbell, \& Sitarenios, 2000; Handley, 1997); better than cognitive ability (Jae, 1997) and academic achievement (Parker, 2002). Other literature suggests that the EQ-i has failed to predict academic success (Newsome, Day, \& Catano, 2000).

Emotional intelligence can be traced to two articles published in 1990 (Mayer, DiPaolo, \& Salovey, 1990; Salovey \& Mayer, 1990). Although the works of Salovey and Mayer are credited with the revitalization of the study of emotional intelligence, the book, Emotional Intelligence (Goleman, 1995), brought emotional intelligence to the public's eye and increased the popularity of the topic in academic and organizational settings.

Although emotional intelligence has received much attention, it has been difficult for researchers to agree on one definition of the construct. Much of the confusion may stem from a construct-oriented issue regarding what emotional intelligence is and what it is not. Within the current emotional intelligence literature, there is a clear distinction between two different models of emotional intelligence: ability-based models and mixed models.

Mayer and Salovey (1997) presented the following definition of emotional intelligence:

... the capacity to reason about emotions, and of emotions to enhance thinking. It includes the ability to accurately perceive emotions, to assess and generate emotions so as to assist thought, to understand emotions and emotional knowledge, and to reflectively regulate emotions so as to promote emotional and intellectual growth. (p. 10)

This model is referred to in the literature as an ability-based model that is different from other models of emotional intelligence that are referred to as mixed models of emotional intelligence. The ability model of emotional intelligence put forth by Mayer and Salovey (1997) presented emotional intelligence as a cognitive ability. As such, the ability-based model of emotional intelligence claims to be more cognitively loaded. Consequently, the Mayer and Salovey model is measured with instruments designed to assess one's knowledge of emotions and one's ability to successfully recognize and work through problems involving emotions and instruments that measure ability. 
Bar-On $(1997,2000,2002)$ had a more broadly defined interpretation of emotional intelligence. Bar-On (2002) explained that emotional intelligence includes one's emotional, personal, and social dimensions of general intelligence:

Emotional intelligence involves abilities, competencies, and skills related to understanding oneself and others, relating to peers and family members, and adapting to changing environmental situations and demands. (p. 1)

This model is known as the mixed model.

Gowing (2001) explained how some of the differences in definitions of emotional intelligence are accounted for by noting that Mayer and Salovey (1997) referred to emotional intelligence as a construct of abilities. They believed emotional intelligence should be thought of as an ability, much like fluid intelligence is an ability. Furthermore, Mayer and Salovey believed that emotional intelligence should be viewed as an actual cognitive and psychological ability that is not completely separate from general mental ability. They posited that, similar to cognitive abilities, emotional intelligence could not be accurately measured with self-report measures that merely asked respondents to rate themselves on their abilities. Instead, Mayer and Salovey stated that abilities could be more accurately measured by gauging one's performance on a test of ability such as the ability to match facial expressions with appropriate moods.

Alternatively, Bar-On (1997) called his model of emotional intelligence a "mixed model" because it is "an array of non-cognitive capabilities, competencies, and skills that influence one's ability to succeed in coping with environmental demands and pressures" (p. 14). This type of model differs from the ability-based model in that the mixed model incorporates other noncognitive constructs that may help identify why some individuals are more successful than others (Mayer, Salovey, \& Caruso, 2000). Because the mixed model contains noncognitive dimensions and because it is a self-report measure, we believe that the mixed-model instruments would be more vulnerable to faking similar to the fakability of personality measures as discussed by Viswesvaran and Ones (1999).

Emotional intelligence tests have been criticized on the grounds that they measure constructs that are primarily covered by personality tests and have been shown to produce significant correlations with personality measures (Davies, Stankov, \& Roberts, 1998; Dawda \& Hart, 2000; Newsome et al., 2000; Schutte et al., 1998). The literature regarding the fakability of personality measures is clear. Viswesvaran and Ones (1999) conducted a meta-analysis to determine whether individuals could fake their responses on the dimensions of The Big Five factors effectively. Included in their investigation were scales used to measure The Big Five dimensions of personality and various social desirability scales. They noted that when respondents were instructed to fake "good," they were able to alter their re- 
sponse scores by almost $1 / 2 S D$. In addition, of all scales investigated, scales measuring social desirability were found to be the most fakable. The relation between personality and emotional intelligence may provide a link between constructs that could indicate that the mixed-model emotional intelligence tests may be fakable. The three most notable similarities are their self-report format, the transparency of the individual items, and the similarity of some of the individual items.

Several studies indicate that noncognitive self-report tests are fakable (Ellingson, Sackett, \& Hough, 1999; Ellingson, Smith, \& Sackett, 2001; McFarland \& Ryan, 2000; Nguyen, 2001; D. S. Ones, Viswesvaran, \& Reiss, 1996; Vasilopoulos, Reilly, \& Leaman, 2000; Viswesvaran \& Ones, 1999; Zickar \& Robie, 1999). Most recently, another article investigated the fakability of a mixed model of emotional intelligence using a measure from Schutte et al. (1998) and found that the measure was indeed fakable and similar in fakability to a personality measure also used in the study (Van Rooy, Viswesvaran, \& Alonso, 2004).

The individual items in self-report personality tests and mixed-model tests are often transparent and are not cognitively loaded. Because the items are transparent and not cognitively challenging, respondents may easily determine how to respond to the items to inflate their score. Several of the items from the Bar-On (2002) Emotional Quotient Inventory Short Form (EQ-i:S) are similar to items used to measure personality dimensions in The Big Five. To illustrate both the transparency and similarity of the items, examples from The Big Five are listed and followed immediately with examples from the EQ-i:S. Because the items contained in the EQ-i:S are proprietary, they have been slightly altered: I often feel blue, Sometimes I get depressed; I talk to a lot of different people at parties, People believe I am sociable; I sympathize with other's feelings, I'm sensitive to other people's feelings. Because of the transparency of the items and their apparent similarity, questions regarding the construct validity of the mixed model of emotional intelligence may arise. Obviously, the mixed model of emotional intelligence contains elements from other constructs, but with the striking similarity of several of the items to items contained in The Big Five, it may lead one to question the extent to which the EQ-i:S and personality tests differ.

The 133-item, Bar-On (1997) EQ-i was developed to measure five main elements of emotional intelligence: (a) Intrapersonal, (b) Interpersonal, (c) Adaptability, (d) Stress Management, and (e) General Mood. It also includes a total score. Bar-On (2000) offered a brief review of the five main components. First, Intrapersonal refers to self-understanding, self-awareness, and the ability to express one's feelings and ideas. Interpersonal is described as the ability to be aware of, appreciate, and understand others' feelings and the ability to establish and maintain mutually satisfying relationships with other individuals. The third component, Adaptability, includes accurately assessing one's feelings with objective external cues and accurately assessing the immediate situation. In addition, Adaptability refers to one's propensity to remain emotionally flexible, to change one's 
thoughts as situations change, and to aid in problem solving. The fourth component, Stress Management, refers to how one copes with stressful situations and controls one's emotions. Finally, General Mood includes traits such as optimism, the tendency to express positive feelings, and enjoying one's self and others. Bar-On (2002) developed a short version of the original 133-item measure (EQ-i:S) that contains 51 questions and measures the same five main components of emotional intelligence.

Because emotional intelligence has been referred to as an indicator of job performance (Bar-On, 2002; Goleman, 1998), the fakability of such measures used to assess one's emotional intelligence should be examined. To date, the fakability of the Bar-On (2002) EQ-i:S, in which respondents are asked to positively manage their impression as they might when applying for a job, has not been measured. Previous researchers have commented on the potential fakability of the Bar-On (1997) EQ-i (Newsome et al., 2000). In a study designed to assess the reliability and validity of the EQ-i, researchers claimed that emotional intelligence scores were not unduly affected by response styles or biases (Dawda \& Hart, 2000). Dawda and Hart, however, did not ask the respondents to attempt to positively manage their impression as they might when responding to pre-employment selection measures. If self-report measures of emotional intelligence are to be used as selection assessment tests, it is essential that their fakability be investigated.

Faking or response distortion has frequently been cited as a problem associated with the use of self-report, noncognitive personnel selection measures (Ellingson \& Sackett, 2001; Ellingson et al., 1999; McFarland \& Ryan, 2000; Nguyen, 2001; Vasilopoulos et al., 2000; Zickar \& Robie, 1999). Although it is widely accepted that noncognitive selection measures such as personality tests are fakable (Ellingson et al., 1999; Ellingson et al., 2001; D. S. Ones et al., 1996; Viswesvaran \& Ones, 1999), issues related to how faking effects the validity of the measures are not so well defined. Some researchers assert that faking does not affect the validity of the measures (Ellingson et al., 1999; Hough, Eaton, Dunnette, Kamp, \& McCloy, 1990; D. S. Ones et al., 1996). Other researchers believe that faking can alter the validity of personality measures (Douglas, McDaniel, \& Snell, 1996; Dunnette, McCartney, Carlson, \& Kirchner, 1962; Rosse, Stecher, Miller, \& Levin, 1998; Schmit \& Ryan, 1993; Viswesvaran \& Ones, 1999; Zickar, Rosse, Levin, \& Hulin 1997).

Bar-On (2002) addressed the topic of response distortion due to social desirability using two different methods. First, Bar-On (2002) noted that respondents with scores $2 S D$ s above the mean are not typical and should be closely examined. The second method of detecting respondents who may attempt to distort their responses uses a positive impression scale. A Positive Impression scale consists of items that are examples of qualities or descriptions of behavior that one might like to be representative of oneself but are probably too positive to be realistic. Scores in excess of $2 S D$ s from the mean standard score are said to be a good indicator of 
overly positive responses (Bar-On, 2002). The manual does not give explicit instructions on what to do about respondents who meet these two criteria, but it appears reasonable to label these respondents as fakers.

This study has two goals. First, we seek to identify the extent to which emotional intelligence as measured by the EQ-i:S can be distinguished from The Big Five. Second, we seek to identify the extent to which the EQ-i:S can be faked; if so, how effective are the two decision rules in identifying faking?

\section{METHOD}

\section{Measures}

The Bar-On (2002) EQ-i:S was used as the measure of emotional intelligence. The scales include an EQ-i:S total score Total EQ, and five substantive subscales: Intrapersonal, Interpersonal, Stress Management, Adaptability, and General Mood. In addition, two validity scales were available. The first validity scale, Inconsistency Index, was used to detect careless or contradicting responses. The second validity scale, Positive Impression, purports to determine if respondents are attempting to provide an exaggerated impression of one's self.

Additional measures were also administered. The Wonderlic Personnel Test (Form A; Wonderlic Inc., 2000) was used as the measure of general cognitive ability. A 50-item measure of The Big Five obtained from the International Personality Item Pool (2002) yielded five scales. Demographic data were collected as was a short survey containing two manipulation check items.

Occasionally, respondents skipped an item. When scoring the EQ-i:S and The Big Five scales, we permitted one item to be missing per scale. The mean of the remaining non-missing items was used to substitute for the missing value.

\section{Procedure}

To assess the fakability of the noncognitive instruments, a within-subjects design was used. The sample of respondents completed a battery of instruments on two different occasions. Groups were randomly assigned the order in which to complete the battery of instruments (i.e., honest then faking or faking then honest). The time between the honest and faking conditions was typically 2 weeks. The Wonderlic test was administered only in the honest condition.

In the honest condition, respondents were instructed to complete the battery of tests as honestly as possible, even if the responses would not seem positive or flattering. In the faking condition, respondents were instructed to respond to the questions as if they were applying for a job they would like to get and to respond in such a way that they believed would guarantee that they are offered the job. Counterbal- 
ancing was used to ensure that any effects due to practice or learning are minimized.

\section{Participants}

Junior and senior level undergraduate business students at a large southeastern, urban university participated in the study for partial class credit or extra credit. All measures in both the honest and faking condition were completed by 251 respondents. Two manipulation check items indicated whether respondents were following the response instructions. Five cases were dropped based on responses to the manipulation check items, leaving 246 respondents. The EQ-i:S response consistency index identified 14 likely random or careless responders who were dropped from the sample, leaving 232 respondents. We built an index of rare responses to the personality inventory that served as a random response scale for the personality items. Three cases were dropped based on that scale, leaving an analysis sample of 229.

The EQ-i:S manual recommends two approaches to identifying fakers separately by age and sex norms. Implementing these rules resulted in a sample of 147 individuals who were not identified as problematic given the two decision rules. Therefore, those who fake in this subsample are those fakers who are not identified by the test's decision rules.

\section{RESULTS}

Table 1 presents a correlation matrix for all study variables. Correlations in the top triangle of the matrix are from the honest condition. Correlates in the bottom half of the triangle are from the faking condition. The diagonal contains the correlation between a scale in the honest condition and the same scale in the faking condition. We note that the intercorrelations among the tests in the honest condition tend to be lower than the intercorrelations in the faking condition. This increase in the magnitude of correlations with faking is consistent with past research showing test structure decay with faking (Griffith, Frei, Snell, Hamill, \& Wheeler, 1997). We also note that the correlations between the noncognitive measures in the Wonderlic tend to be low in the honest condition and increase somewhat in the faking condition. This is consistent with the notion that success in faking is somewhat dependent on cognitive ability.

Table 2 presents the results of a regression analysis to predict the EQ-i:S total score in the honest condition. The independent variables are The Big Five scales in the honest condition. The multiple correlation was .79. All The Big Five measures significantly contribute to the prediction of the EQ-i:S total score. Emotional Stability has the largest standardized beta weight followed by Agreeableness, Consci- 


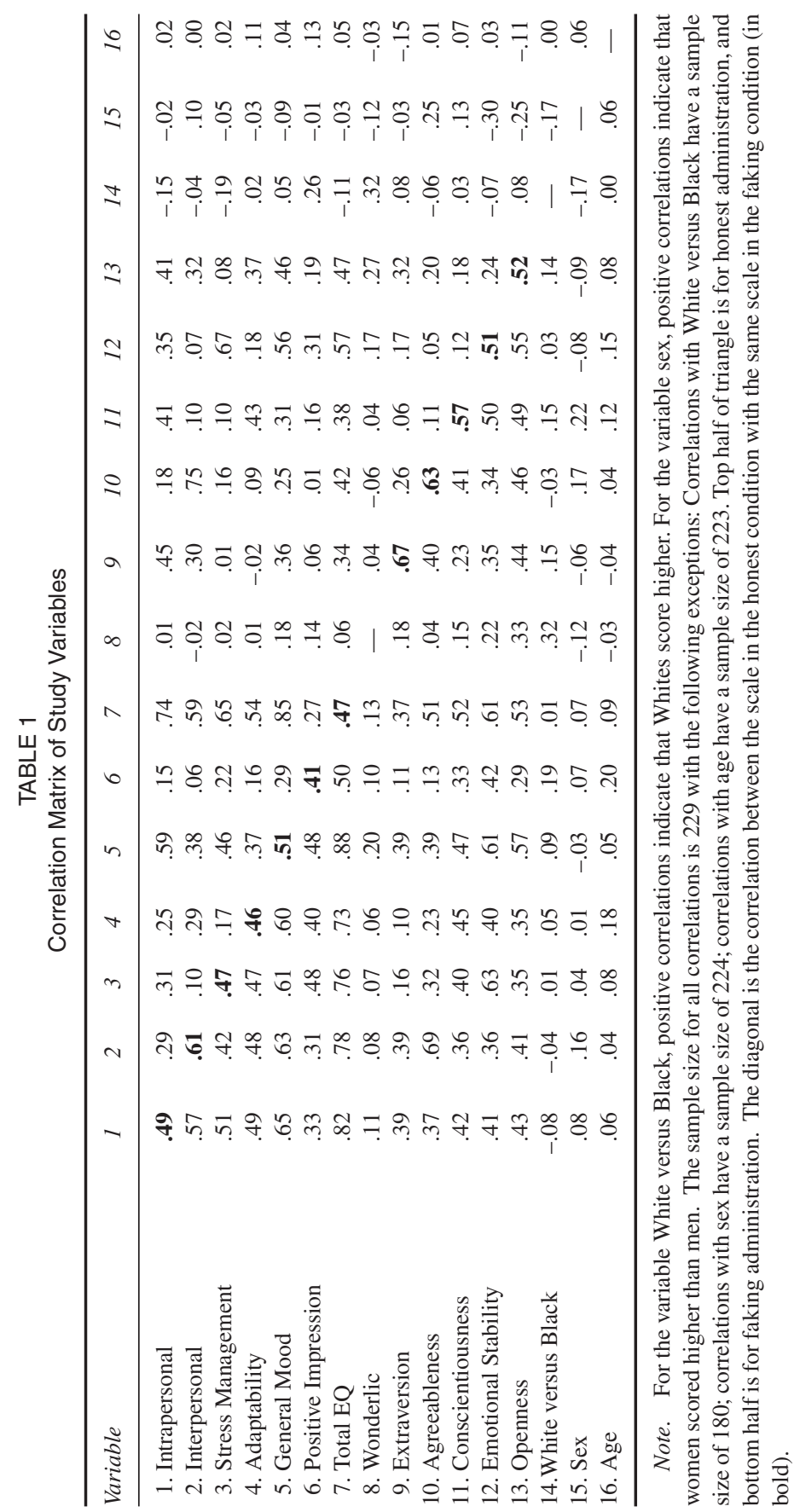


TABLE 2

Predicting the Total EQ When Responded to Honestly

\begin{tabular}{lccccc}
\hline & & & & \multicolumn{2}{c}{$95 \%$ CI $\beta$} \\
\cline { 5 - 6 } Variable & $\beta$ & $T$ & & \multicolumn{1}{c}{$\begin{array}{l}\text { Lower } \\
\text { Bound }\end{array}$} & $\begin{array}{l}\text { Upper } \\
\text { Bound }\end{array}$ \\
\hline Extraversion & 0.097 & 2.147 & 0.033 & 0.004 & 0.082 \\
Agreeableness & 0.296 & 6.817 & 0.000 & 0.128 & 0.233 \\
Conscientiousness & 0.240 & 5.666 & 0.000 & 0.089 & 0.184 \\
Emotional Stability & 0.457 & 10.609 & 0.000 & 0.166 & 0.242 \\
Openness & 0.231 & 5.084 & 0.000 & 0.088 & 0.199 \\
\hline
\end{tabular}

Note. The multiple correlation is .79 $\left(R^{2}=.62\right)$.

entiousness, Openness, and Extraversion. Table 1 provides the zero-order correlations between the total score and each of The Big Five. For the honest condition, these correlations are .34 (Extraversion), .42 (Agreeableness), .38 (Conscientiousness), .57 (Emotional Stability), and .47 (Openness to Experience). Therefore, the Total EQ score appears to be primarily an aggregation of The Big Five constructs.

Table 3 presents the means, standard deviations, and reliabilities of all EQ-i:S substantive scales, the EQ-i:S Positive Impression scale, and The Big Five scales. The results are presented for both the honest condition and the faking condition. The standardized mean difference $(d)$ is presented for each scale. The $d$ statistic summaries the magnitude of the faking effect for each scale and is expressed in standard deviation units. Therefore, the .83 faking effect for the Total EQ scale indicates that fakers, on average, can raise their scores .83 SDs over their honest responses. Comparing the $d$ across scales is hampered by the differences in reliabilities across the various scales. We corrected the $d$ based on the reliability of the scale in the honest condition. The resulting statistic $\left(d_{c}\right)$ is the magnitude of faking expected if all scales had perfect reliability. Although this corrected $d_{c}$ overestimates the degree of observed faking, it permits a comparison of faking magnitude that controls for reliability differences across scales. All EQ-i:S scales and all The Big Five scales showed non-zero faking effects. The faking effect size for the Total EQ score was the largest (.83). The large magnitude of this scale is, in part, due to the scale's large reliability.

The analyses in Table 3 based on 229 respondents may not be considered an accurate evaluation of faking in the EQ-i:S because it includes respondents that could have been identified as fakers by the two faking indicators in the EQ-i:S. To address this potential criticism, we dropped the respondents who would have been identified as fakers using the decision rules in the EQ-i:S manual. This reduced the analysis sample to 147 . To the extent that there is faking in the remaining respondents, it would be faking that is not identified using decision rules in the EQ-i:S 
TABLE 3

Sample Size, Mean, Standard Deviation, $d$ Statistic, $d_{c}$ statistic Corrected for Reliability

\begin{tabular}{|c|c|c|c|c|c|c|c|c|}
\hline \multirow[b]{2}{*}{ Variable } & \multicolumn{3}{|c|}{ Honest Condition } & \multicolumn{3}{|c|}{ Faking Condition } & \multicolumn{2}{|c|}{$\begin{array}{c}\text { Faking } \\
\text { Effect Size } \\
\text { Corrected }\end{array}$} \\
\hline & $M$ & $\sigma$ & $\alpha$ & $M$ & $\sigma$ & $\alpha$ & $d$ & $d_{c}^{*}$ \\
\hline \multicolumn{9}{|l|}{ All data $(N=229)$} \\
\hline Total EQ & 35.64 & 3.66 & .89 & 38.86 & 4.11 & .95 & .83 & .88 \\
\hline Intrapersonal & 39.39 & 5.81 & .88 & 43.00 & 5.63 & .83 & .63 & .67 \\
\hline Interpersonal & 41.22 & 6.11 & .80 & 43.83 & 5.18 & .82 & .51 & .57 \\
\hline Stress Management & 30.02 & 6.24 & .84 & 33.92 & 5.53 & .86 & .66 & .72 \\
\hline Adaptability & 27.66 & 3.83 & .76 & 29.77 & 3.91 & .79 & .55 & .63 \\
\hline General Mood & 39.92 & 5.76 & .85 & 43.77 & 5.50 & .87 & .69 & .75 \\
\hline Positive Impression & 14.85 & 4.90 & .77 & 18.02 & 6.11 & .83 & .57 & .65 \\
\hline Extraversion & 33.12 & 8.25 & .91 & 35.96 & 7.54 & .89 & .36 & .38 \\
\hline Agreeableness & 39.99 & 6.00 & .86 & 41.70 & 5.53 & .81 & .30 & .32 \\
\hline Conscientiousness & 38.45 & 6.43 & .84 & 42.82 & 6.06 & .86 & .70 & .76 \\
\hline Emotional Stability & 32.67 & 8.18 & .90 & 38.48 & 7.59 & .88 & .74 & .78 \\
\hline Openness & 37.20 & 5.88 & .82 & 40.22 & 5.68 & .81 & .52 & .57 \\
\hline \multicolumn{9}{|l|}{ Screened data $(N=147)$} \\
\hline Total EQ & 34.92 & 3.62 & .91 & 37.13 & 3.59 & .93 & .62 & .65 \\
\hline Intrapersonal & 39.03 & 5.83 & .80 & 41.24 & 5.42 & .80 & .40 & .45 \\
\hline Interpersonal & 40.14 & 5.00 & .78 & 42.18 & 5.11 & .80 & .40 & .45 \\
\hline Stress Management & 29.56 & 6.14 & .84 & 32.11 & 5.53 & .84 & .44 & .48 \\
\hline Adaptability & 26.91 & 3.46 & .71 & 28.39 & 3.45 & .71 & .43 & .51 \\
\hline General Mood & 38.95 & 5.73 & .84 & 41.75 & 5.34 & .84 & .51 & .56 \\
\hline Positive Impression & 13.59 & 4.28 & .69 & 14.97 & 4.55 & .68 & .31 & .38 \\
\hline Extraversion & 33.09 & 7.94 & .90 & 35.12 & 7.57 & .90 & .26 & .27 \\
\hline Agreeableness & 39.19 & 6.05 & .86 & 40.50 & 5.62 & .82 & .23 & .25 \\
\hline Conscientiousness & 37.19 & 6.20 & .82 & 40.82 & 5.84 & .84 & .60 & .66 \\
\hline Emotional Stability & 32.14 & 7.93 & .90 & 36.10 & 7.19 & .88 & .53 & .56 \\
\hline Openness & 36.52 & 5.83 & .82 & 38.49 & 5.51 & .81 & .35 & .39 \\
\hline
\end{tabular}

Note. $\quad d=$ standard mean difference. The reliability of the EQ-i:S was estimated as the reliability of a linear composite of its components (Nunnally \& Bernstein, 1994, p 268). Corrected $d_{c}$ statistics were determined by dividing the observed $d$ statistic by the square root of the scale's reliability based on the honest condition administration.

manual. The results of the faking analysis for the reduced sample are shown in the lower half of Table 3. As was the case for the analysis of the full data set, both the Total EQ score and its subscales as well as The Big Five scales showed considerable faking.

As evidenced by Table 3, the magnitude of faking was decreased in all categories of the EQ-i:S as respondents were identified and removed by the elements of the instrument designed to detect response distortion. Although the EQ-i:S was 
able to detect respondents ( 82 of the original 229) who exhibited extreme levels of faking, respondents in the screened data were still able to raise their scores anywhere from $1 / 3 S D$ to $2 / 3 S D$ from their honest score without being detected. The greatest level of faking in both sample sizes was the composite total emotional intelligence score that decreased from $d=.83$ in the total sample to $d=.62$ in the screened sample. Similarly, as the sample decreased by rejecting fakers detected by the EQ-i:S, faking on the different personality dimensions decreased as well.

Table 4 shows the number and percentage of individuals who were identified as faking using the two screens documented in the EQ-i:S manual: $8.7 \%$ of the honest respondents were considered faking, and $31 \%$ of the fakers were identified as faking using these screens. The two screens did not identify $69 \%$ of the faking respondents sample as faking. Although the results in the bottom half of Table 3 show that these unidentified fakers did indeed fake on average, the EQ-i:S criteria for identifying fakers is far from accurate.

Table 5 examines the $69 \%$ of those in the faking condition that were not identified as fakers using the two screens. The table shows the percentage and number of these individuals who were able to increase their scores by varying magnitudes. Of these 147 respondents not identified as fakers, $57.8 \%$ were able to improve their score by at least $.25 S D$ s (the honest group standard deviation of 3.66 was used in

TABLE 4

Percentages and Counts of Honest and Faking Respondents Who Met Various Decision Criteria

\begin{tabular}{lcc}
\hline Decision Criteria & \% Honest (Count) & \% Faking (Count) \\
\hline Screen 1. Exceed 2 $\sigma$ on Total EQ & $0.4 \%(1)$ & $15.7(36)$ \\
Screen 2. Exceeded 2 $\sigma$ on Positive & $8.3 \%(19)$ & $24.0 \%(55)$ \\
$\quad$ Impression Scale & $8.7 \%(20)$ & $31.0 \%(71)$ \\
Meet either Screen 1 or Screen 2 & & \\
\hline
\end{tabular}

TABLE 5

Percentage and Count of Respondents Who Were Not Identified as Fakers on the Two Screens but Who Had Varying Levels of Score Improvement on the Total EQ Scale

\begin{tabular}{lcc}
\hline Variable & $\%$ & Count \\
\hline Improved on Total EQ Scale by $.25 \sigma$ or higher & 57.8 & 85 \\
Improved on Total EQ Scale by .50 $\sigma$ or higher & 42.9 & 63 \\
Improved on Total EQ Scale by $1 \sigma$ or higher & 28.6 & 42 \\
Improved on Total EQ Scale by 1.5 $\sigma$ or higher & 13.6 & 20 \\
Improved on Total EQ Scale by $2 \sigma$ or higher & 8.8 & 13 \\
\hline
\end{tabular}

Note. $\quad N=147$. 
these calculations). Sixty-three individuals (42.9\%) were able to improve their score by at least $.5 S D \mathrm{~s}, 28.6 \%$ improved their score by at least $1 S D, 13.6 \%$ improved their score by at least $1.5 S D \mathrm{~s}$, and $8.8 \%$ improved their score by at least 2 $S D$ s. This group, all of who escaped detection using decision rules in the EQ-i:S manual, were able to successfully improve their scores, on average, by substantial amounts. To adapt from Elvis Presley, "there was a whole lot of faking going on."

Table 6 presents regression analyses to predict faking on the Total EQ scale and the subscales. Hierarchical regression analyses were used to predict the change in scores from honest to faking conditions (Edwards \& Parry, 1993). The dependent variable was the EQ-i:S scale in the faking condition. The independent variable in the first step was the honest condition version of the same scale. Therefore, for example, in the regression to predict faking on the Total EQ scale, the dependent variable is the faking condition Total EQ scale, and the sole independent variable in the first step is the honest condition Total EQ scale. The second step of the regression equation contained the Wonderlic and the Big 5 scales from the honest condition. Table 6 also presents a second set of hierarchical regressions in which the second step independent variables are limited to the Wonderlic and Agreeableness.

The results indicate that faking on the EQ-i:S is a function of cognitive ability and personality (primarily agreeableness). Although conscientiousness was consistently and positively related to the ability to fake, the alternative Step 2 of the regression equation demonstrated that cognitive ability and agreeableness are the dominant predictors of one's ability to fake this data. The extent to which the level of faking can be explained through cognitive ability and agreeableness is intuitive. First, respondents with higher cognitive ability are more likely than respondents with lower levels of cognitive ability to be able to recognize opportunities within the instrument to present themselves most favorably. Their increased level of reasoning and ability enables them to determine how best to fake "good" on a self-report instrument. In addition, respondents with higher levels of agreeableness are more likely than respondents with lower levels of agreeableness to be willing to follow directions and cooperate with the honest and faking instructions.

\section{DISCUSSION}

The first goal of this article was to identify the extent to which a mixed model of emotional intelligence, EQ-i:S, is related to The Big Five. The regression analysis shown in Table 2 yielded a multiple correlation of . 79 with the Total EQ scale, indicating that the majority of variance in the EQ-i:S can be attributed to The Big Five constructs. The three most related Big Five variables (Emotional Stability, Conscientiousness, and Agreeableness) represent a higher order factor of The Big Five (Digman, 1997) that is typically called socialization. This pattern of relations is common to many personality composite measures including integrity tests (D. L. 


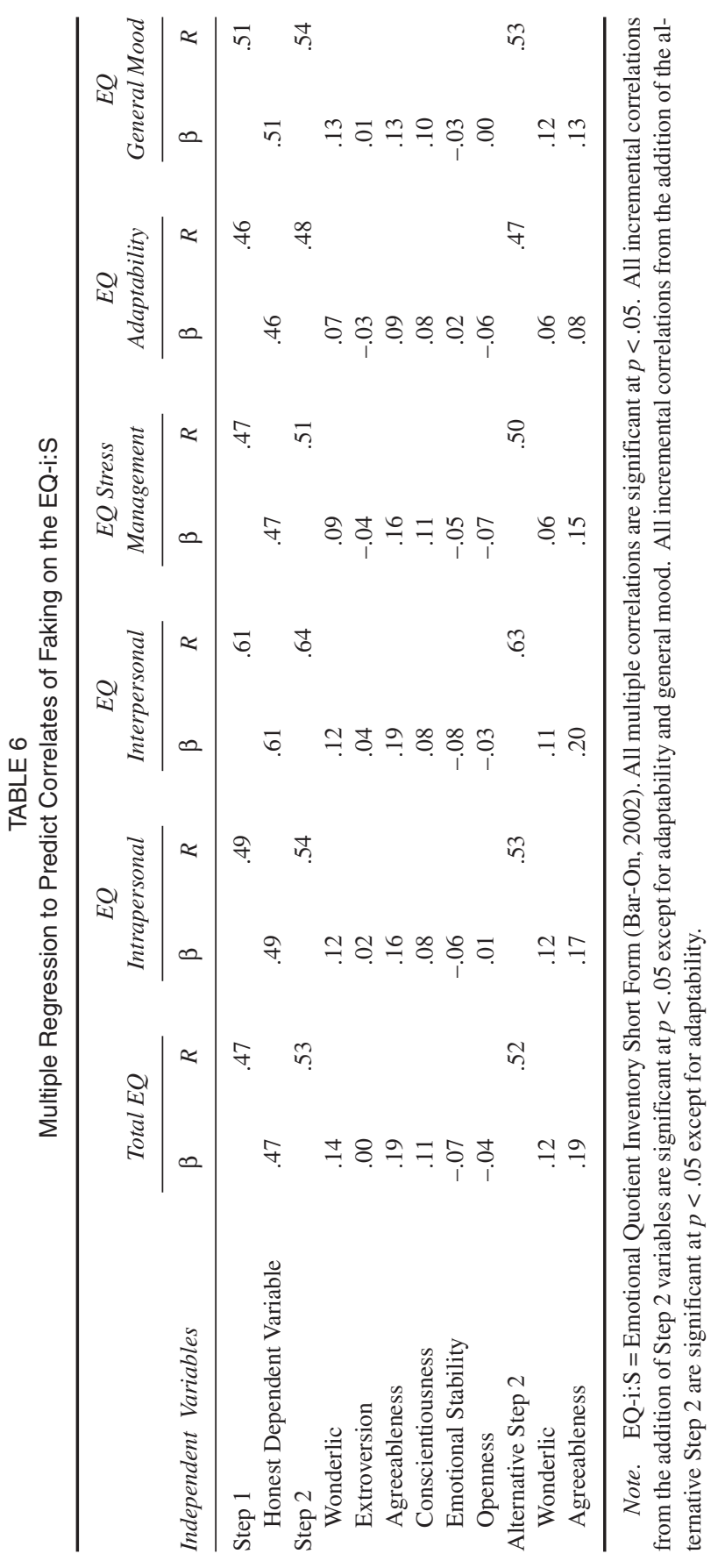


Ones, Viswesvaran, \& Schmidt, 1993) and customer service tests (Frei \& McDaniel, 1998). Therefore, the EQ-i:S might best be viewed as an aggregate of The Big Five constructs. We concur with Schaie (2001) that measures of emotional intelligence need to show divergent validity from other constructs before the construct of emotional intelligence can be viewed as credible. In this sample, the EQ-i:S is very redundant with The Big Five; thus, it is arguable whether there is empirical evidence in these data to support the existence of a construct called emotional intelligence. Other emotional intelligence tests might yield evidence of the divergence of these measures from well-known constructs such as The Big Five. However, based on the evidence in this study, we believe that the EQ-i:S is best viewed as an aggregation of the The Big Five that emphasizes the constructs related to socialization.

The second goal of this article is to address the extent to which a mixed-model emotional intelligence test, the EQ-i:S, can be faked by respondents motivated to improve their score. Although the different indexes of the EQ-i:S were able to identify $31 \%$ of the faking respondents (see Table 4 ), most of the respondents were able to increase their score by faking and not be identified.

Tables 3 shows the EQ-i:S to be substantially fakable with larger magnitude faking effect sizes than The Big Five measures. Tables 3, 4, and 5 show that even when one excludes the respondents who would have been identified as fakers using the two screens in the EQ-i:S manual, there is still substantial opportunity to fake the instrument.

Table 6 shows that cognitive ability and Agreeableness predicted the degree of faking. We suggest that cognitive ability is the primary correlate of the ability to fake in operational testing. More cognitively gifted individuals do better at identifying the responses that yield high scores. We suggest that the agreeableness correlate of faking in this study is an artifact of instructing the respondents to fake. The agreeable individuals were more willing to follow the instructions to fake.

\section{Limitations}

Although the study indicates that the EQ-i:S is substantially fakable, there are several limitations to the study. Limitations pertaining to the difference between ability and motivation to fake, the sample of respondents, as well as the actual base rate of faking must be considered. Before the subject of motivation to fake is addressed, it is important to distinguish between one's ability to fake and one's motivation to fake. This study measures only one's ability to fake. Because the respondents were instructed to fake, the instructions essentially equate people on their motivation to fake, and the amount of faking in an actual applicant setting may vary.

Our results address the EQ-i:S. Other mixed-model measures may or may not be as subject to faking as the EQ-i:S or as redundant with The Big Five constructs. It is, however, presumed that because other mixed models of emotional intelli- 
gence use self-report measures, they are likely to be highly fakable as well. Future research, both replicating this study and examining the fakability of other mixed models of emotional intelligence, is warranted.

Also, this study does not address potential faking problems in ability-based models of emotional intelligence (Mayer \& Salovey, 1997). The Mayer et al. (2000) model is not considered a mixed model of emotional intelligence. It is referred to as an ability-based model that does not solely rely on a self-report measure. Finally, as indicated by Viswesvaran and Ones (1999), the within-subjects design of the study may have increased the level of faking due to practice and learning effects.

\section{CONCLUSION}

This study raises two serious concerns about the EQ-i:S and potentially all mixed models of emotional intelligence. First, the measure, when responded to honestly, is primarily assessing an aggregate of The Big Five. As such, it does not appear useful to postulate a unique construct of emotional intelligence to understand what this test measures. A more accurate and data-based description of this test would be "an aggregate of The Big Five." Second, like other measures of The Big Five, respondents can easily misrepresent themselves on the test to obtain a high score. We encourage additional research on the development of emotional intelligence measures that show differentiation from well-established constructs and that are resistant to faking.

\section{REFERENCES}

Bachman, J., Stein, S., Campbell, K., \& Sitarenios, G. (2000). Emotional intelligence in the collection of debt. International Journal of Selection and Assessment, 8, 176-182.

Barling, J., Slater, F., \& Kelloway, E. K. (2002). Transformational leadership and emotional intelligence: An exploratory study. Journal of Applied Psychology, 81, 827-832.

Bar-On, R. (1997). Bar-On Emotional Quotient Inventory (EQ-i): Technical manual. Toronto, Canada: Multi-Health Systems.

Bar-On, R. (2000). Emotional and social intelligence: Insights from the Emotional Quotient Inventory. In J. D. A. Parker (Ed.), The handbook of emotional intelligence (pp. 363-390). San Francisco: Jossey-Bass.

Bar-On, R. (2002). Bar-On Emotional Quotient Inventory: Short Technical Manual. Toronto, Canada: Multi-Health Systems.

Davies, M., Stankov, L., \& Roberts, R. D. (1998). Emotional intelligence: In search of the elusive construct. Journal of Personality and Social Psychology, 75, 989-1015.

Dawda, D., \& Hart, S. D. (2000). Assessing emotional intelligence: Reliability and validity of the Bar-On Emotional Quotient Inventory (EQ-i) in university students. Personality and Individual Differences, 28, 797-812. 
Digman, J. M. (1997). Higher-order factors of the Big Five. Journal of Personality \& Social Psychology, 73, 1246-1256.

Douglas, E. F., McDaniel, M. A., \& Snell, A. F. (1996, August). The validity of non-cognitive measures decays when applicants fake. Paper presented at the 56th annual meeting of the Academy of Management, Cincinnati, $\mathrm{OH}$.

Dunnette, M. D., McCartney, J., Carlson, H. C., \& Kirchner, W. K. (1962). A study of faking behavior on a forced-choice self-description checklist. Personnel Psychology, 15, 13-24.

Edwards, J. R., \& Parry, M. E. (1993). On the use of polynomial regression equations as an alternative to difference scores in organizational research. Academy of Management Journal, 36, 1577-1613.

Ellingson, J. E., Sackett, P. R., \& Hough, L. M. (1999). Social desirability correlations in personality measurement: Issues of applicant comparison and construct validity. Journal of Applied Psychology, 84, 155-166.

Ellington, J. E., Smith, D. B., \& Sackett, P. R. (2001). Investigating the influence of social desirability on personality factor structure. Journal of Applied Psychology, 86, 122-133.

Frei, R., \& McDaniel, M. A. (1998). The validity of customer service orientation measures in employee selection: A comprehensive review and meta-analysis. Human Performance, 11, 1-27.

Goleman, D. (1995). Emotional intelligence. New York: Bantam.

Goleman, D. (1998). Working with emotional intelligence. New York: Bantam.

Gowing, M. K. (2001). Measurement of individual emotional competence. In D. Goleman (Ed.), The emotionally intelligent workplace (pp. 83-131). San Francisco: Jossey-Bass.

Griffith, R. L., Frei, R. L., Snell, A. F., Hamill, L. S., \& Wheeler, J. K. (1997, April). Warnings versus no-warnings: Differential effect of method bias. Paper presented at the 12th annual conference of the Society of Industrial and Organizational Psychology, St. Louis, MO.

Handley, R. (1997). Emotional intelligence. Recruiter, April, 10-11.

Hough, L. M., Eaton, N. K., Dunnette, M. D., Kamp, J. D., \& McCloy, R. A. (1990). Criterion-related validities of personality constructs and the effects of response distortion on those validities. Journal of Applied Psychology, 75, 581-595.

Humphrey, R. H. (2002). The many faces of emotional leadership. The Leadership Quarterly, 13, 493-504.

International Personality Item Pool. (2002). A scientific collaboratory for the development of advanced measures of personality traits and other individual differences. Retrieved September 3, 2002, from http://ipip.ori.org/

Jae, J. H. (1997). Emotional intelligence and cognitive ability as predictors of job performance in the banking sector. Unpublished master's thesis, Ateneo de Manila University, Philippines.

Kellett, J. B., Humphrey, R. H., \& Sleeth, R. G. (2002). Empathy and complex task performance: Two routes to leadership. The Leadership Quarterly, 13, 523-544.

Mayer, J. D., DiPaolo, M. T., \& Salovey, P. (1990). Perceiving affective content in ambiguous visual stimuli: A component of emotional intelligence. Journal of Personality Assessment, 54, 772-781.

Mayer, J. D., \& Salovey, P. (1997). What is emotional intelligence? In D. J. Sluyter(Ed.), Emotional development andemotional intelligence: Implications for educators (pp. 3-31). New York: Basic Books.

Mayer, J. D., Salovey, P., \& Caruso, D. (2000). Models of emotional intelligence. In R. J. Sternberg (Ed.), Handbook of intelligence (pp. 396-420). New York: Cambridge University Press.

McFarland, L. A., \& Ryan, A. M. (2000). Variance in faking across noncognitive measures. Journal of Applied Psychology, 85, 812-821.

Newsome, S., Day, A. L., \& Catano, V. M. (2000). Assessing the predictive validity of emotional intelligence. Personality and Individual Differences, 29, 1005-1016.

Nguyen, N. (2001). Faking in situational judgment tests: An empirical investigation of the work judgment survey. Unpublished doctoral dissertation, Virginia Commonwealth University, Richmond.

Nunnally, J. C., \& Bernstein (1994). Psychometric theory (3rd ed.). New York, NY: McGraw-Hill. 
Ones, D. L., Viswesvaran, C., \& Schmidt, F. L. (1993). Comprehensive meta-analysis of integrity test validities: Findings and implications for personnel selection and theories of job performance. Journal of Applied Psychology, 78, 679-703.

Ones, D. S., Viswesvaran, C., \& Reiss, A. D. (1996). Role of social desirability in personality testing for personnel selection: The red herring. Journal of Applied Psychology, 81, 660-679.

Parker, J. D. A. (2002, June). Emotional intelligence and academic success: Examining the transition from high school to university. Paper presented at the annual meeting of the Canadian Psychological Association, Vancouver, British Columbia.

Rosse, J. G., Stecher, M. D., Miller, J. L., \& Levin, R. A. (1998). The impact of response distortion on preemployment personality testing and hiring decisions. Journal of Applied Psychology, 83, 634-644.

Salovey, P., \& Mayer, J. D. (1990). Emotional intelligence. Imagination, Cognition, and Personality, 9, $185-211$.

Schaie, K. W. (2001). Emotional intelligence: Psychometric status and developmental characteristics-Comment on Roberts, Zeidner, and Matthews (2001). Emotion, 1, 243-248.

Schmit, M. J., \& Ryan, A. M. (1993). The Big Five in personnel selection: Factor structure in applicant and nonapplicant populations. Journal of Applied Psychology, 78, 966-974.

Schutte, N. S., Malouff, J. M., Hall, L. E., Haggerty, D. J., Cooper, J. T., Golden, C. J., et al. (1998). Development and validation of a measure of emotional intelligence. Personality and Individual Differences, 25, 167-177.

Van Rooy, D. L., Viswesvaran, C., \& Alonso, A. (2004, April). The susceptability of a mixed model measure of emotional intelligence to faking: A Solomon 4-group design. Paper presented at the 19th annual meeting of the Society for Industrial and Organizational Psychology, Chicago, IL.

Vasilopoulos, N. L., Reilly, R. R., \& Leaman, J. A. (2000). The influence of job familiarity and impression management on self report measure scale scores and response latencies. Journal of Applied Psychology, 85, 50-64.

Viswesvaran, C., \& Ones, D. S. (1999). Meta-analyses of fakability estimates: Implications for personality measurement. Educational and Psychological Measurement, 59, 197-210.

Wolf, S. B., Pescosolido, A. T., \& Druskat, V. U. (2002). Emotional intelligence as the basis of leadership emergence in self-managing teams. The Leadership Quarterly, 13, 505-522.

Wonderlic, Inc. (2000). Wonderlic Personnel Test: Form A. Libertyville, IL: Author.

Zickar, M. J., \& Robie, C. (1999). Modeling faking good on personality items. Journal of Applied Psychology, 84, 551-563.

Zickar, M. J., Rosse, J. G., Levin, R. A., \& Hulin, C. L. (1997). Modeling the effects offaking on personality tests. Unpublished manuscript, Bowling Green State University, $\mathrm{OH}$. 